\title{
Resolution of vitreomacular traction following intravitreal ranibizumab in cases of ocular toxoplasmosis with choroidal neovascularization
}

This article was published in the following Dove Press journal:

Therapeutics and Clinical Risk Management

16 October 2013

Number of times this article has been viewed

\author{
Petros Petrou ${ }^{1,2}$ \\ Ilias Georgalas ${ }^{2}$ \\ Nikolaos Markomichelakis ${ }^{2}$ \\ loannis Vergados ${ }^{2}$ \\ Emanuela Gianakaki² \\ Alexander Rouvas ${ }^{2}$ \\ 'Moorfields Eye Hospital, London, \\ UK; ${ }^{2}$ Ophthalmology Department, \\ University of Athens, Athens, Greece
}

Purpose: To present the occurrence of the resolution of vitreomacular traction following intravitreal ranibizumab in two patients with inflammatory choroidal neovascular (CNV) membrane with a background of ocular toxoplasmosis.

Methods: Interventional case report.

Results: A 21-year-old Caucasian woman and a 52-year-old Caucasian man both presented with vitreomacular traction with coexistent classic $\mathrm{CNV}$ membrane and a background of ocular toxoplasmosis. They both received an intravitreal injection of ranibizumab in an effort to control the underlying $\mathrm{CNV}$ membrane. A resolution of the vitreomacular traction was observed within 1 week of the intravitreal injection in both cases.

Conclusion: To the best of our knowledge, this is the first reported case of vitreomacular traction resolution in two patients with ocular toxoplasmosis following ranibizumab administration. Of course, further studies are needed in order to adequately support this association.

Keywords: vitreomacular traction, spontaneous resolution, ranibizumab, intravitreal, inflammation

\section{Introduction}

Although vitreomacular traction (VMT) syndrome comprises a well-defined clinical entity, VMT with a background of inflammation has been poorly documented. ${ }^{1,2}$ In VMT, eyes have a risk of developing cystoid macular changes that tend to persist, with a subsequent decrease in visual acuity. ${ }^{3}$ In many cases with persistent macular edema, surgical intervention to relieve the traction represents the optimal therapeutic approach in order to achieve visual recovery. The latter is extremely challenging in eyes with a history of severe inflammation.

Moreover, spontaneous resolution of VMT has been reported to occur in $11 \%$ of patients, ${ }^{3}$ although the respective incidence in patients with inflammatory VMT has not been established. We herein present two patients with VMT with a background of toxoplasma-related choroidal neovascular (CNV) membrane who demonstrated resolution of the vitreous traction within 1 week ( 5 days and 7 days) of an intravitreal ranibizumab injection.

\section{Materials and methods}

This is an interventional case report of two patients.

\section{Results}

Ophthalmology Department,

I54 Mesogeion Avenue,

University of Athens, Athens, Greece

Tel +302106776499

Fax +302106776499

Email petrospetrou2@yahoo.com

\section{Presentation of case I}

A 21-year-old Caucasian woman was referred to our department for further evaluation of her ocular status. She had a 2-year history of ocular toxoplasmosis in her left eye 
(LE) for which she had received systemic treatment with pyrimethamine, sulfadiazine, clindamycin, and prednisone. Although the inflammation was controlled and visual acuity initially improved, the patient was complaining of gradual visual deterioration over the last year.

Best-corrected visual acuity (BCVA) was 20/400 in the LE and 20/20 in the right eye (RE). Anterior segment examination was unremarkable and intraocular pressure was within normal limits bilaterally. Dilated fundus examination revealed two chorioretinal scars within the retinal arcades. Fundus fluorescein angiography showed the existence of a classic CNV, and optical coherence tomography (OCT) demonstrated a VMT with coexistent intraretinal fluid (Figure 1). The patient underwent an intravitreal injection of ranibizumab $(0.5 \mathrm{mg})$ in an effort to control the CNV. Five days later she contacted the department reporting a sudden improvement in visual acuity. Examination at that point revealed a BCVA of 20/100, and OCT showed a resolution of the vitreous traction with improvement of macular edema (Figure 1). Visual acuity remains at the same level at 6 months' follow-up.

\section{Presentation of case 2}

A 52-year-old Caucasian man presented to the department complaining of visual deterioration of 2 months' duration. He had a known history of ocular toxoplasmosis in the RE for which he had received treatment with systemic azithromycin and prednisone 6 months prior to presentation. According to his notes, he initially responded well to treatment and the inflammation subsided.

On examination, his BCVA was 20/400 in the RE and 20/20 in the LE. Anterior segment examination and intraocular pressure measurement were within normal limits in both eyes. No signs of inflammation were present in either eye, and dilated fundus examination, fluorescein angiography, and OCT demonstrated the existence of macular edema with VMT with a background of a classic inflammatory neovascular membrane in the RE (Figure 2). The patient was injected with $0.5 \mathrm{mg}$ of intravitreal ranibizumab in order to control the CNV. Follow-up 1 week later, including OCT, revealed a BCVA of 20/50 in the RE with a vitreous traction resolution and reduced macular edema (Figure 2). At 3 months' follow-up, BCVA was 20/50.

\section{Discussion}

VMT syndrome represents a complication of a partial posterior vitreous detachment causing traction on the retina in the posterior pole. Typically, the cortical vitreous remains attached to the retina at the macula and the optic nerve head, exerting persistent anteroposterior traction on the retina and leading to visual loss due to cystoid macular edema and tractional retinal detachment of variable severity and extent. ${ }^{3}$ VMT with a background of ocular toxoplasmosis has been poorly described in the literature, ${ }^{2}$ and therefore the
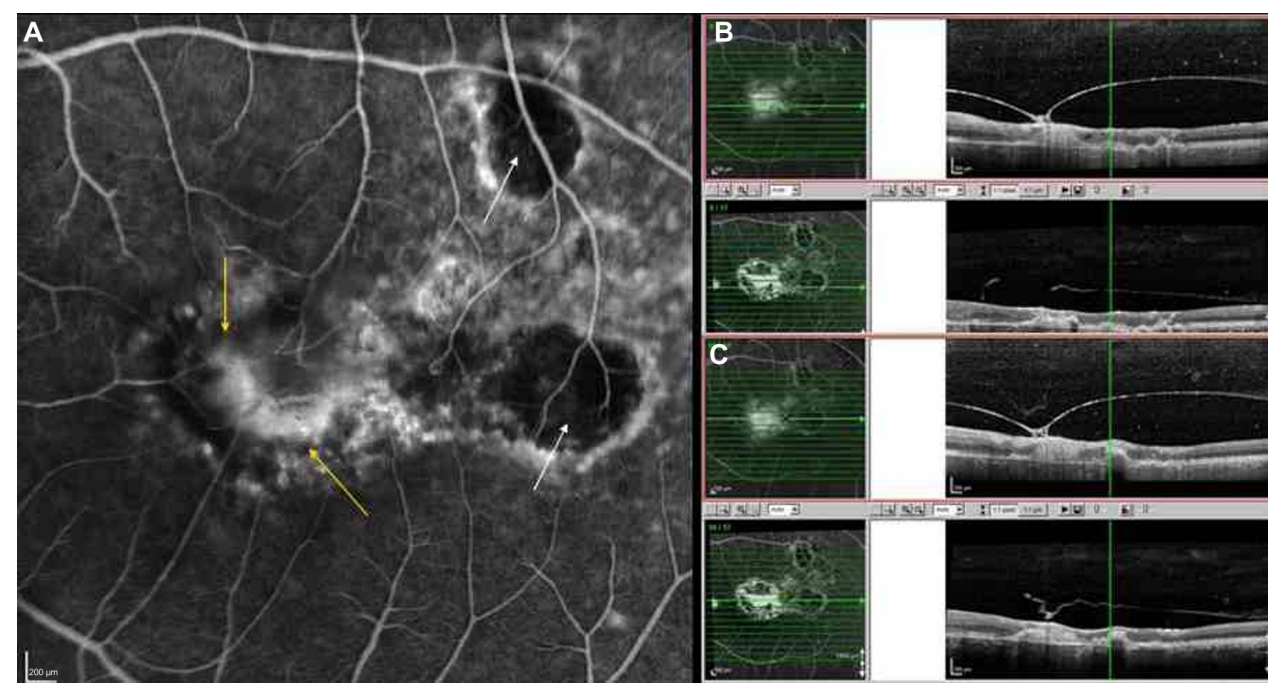

Figure I (A) Fluorescein angiography of the left eye demonstrating two chorioretinal scars (white arrows) and a classic choroidal neovascular membrane (yellow arrows). (B) Spectral domain optical coherence tomography (Spectralis ${ }^{\circledR}$ HRA-OCT, Heidelberg Engineering, Inc., Carlsbad, CA, USA) point-to-point registration before and after the administration of the intravitreal injection of ranibizumab, demonstrating a thick, hyper-reflective, and taut posterior hyaloid, partially detached from the posterior pole exerting traction on the fovea. The steep V-shaped hyaloids curve and the thickened cystoid fovea are suggestive of vitreomacular traction (before), which demonstrate a resolution and reduction of macular thickness (after). (C) Spectral domain optical coherence tomography point-to-point registration at the next level, showing the release of the vitreous traction. 

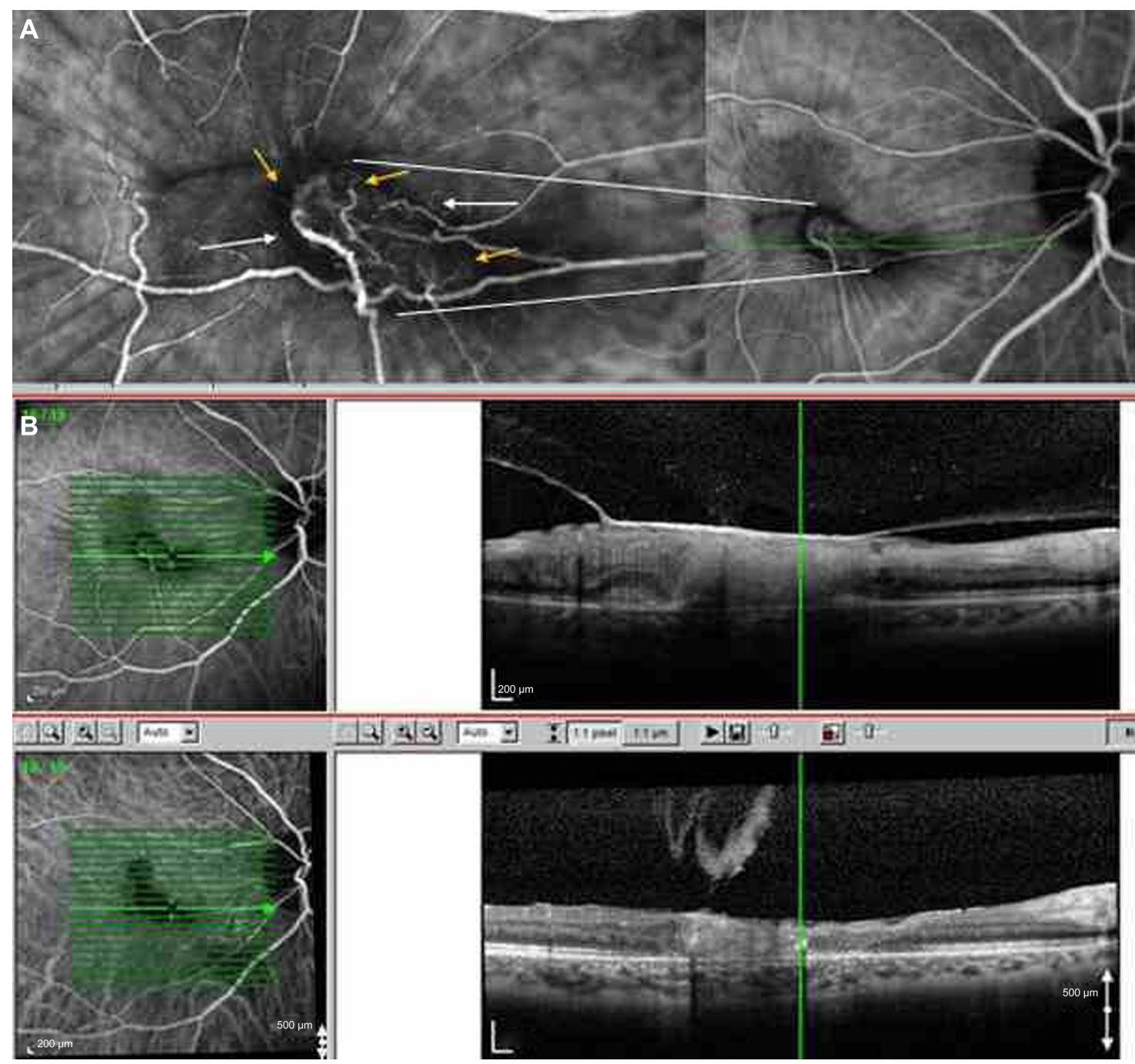

Figure 2 (A) Indocyanine green angiography of the right eye (with magnified foveal area), demonstrating a classic choroidal neovascular membrane (white arrows) with retinal-choroidal anastomosis (yellow arrows). (B) Spectral domain optical coherence tomography (Spectralis ${ }^{\circledR}$ HRA-OCT, Heidelberg Engineering, Inc., Carlsbad, CA, USA) point-to-point registration, showing a taut, V-shaped, hyper-reflective posterior hyaloid attached on the fovea with coexistent macular edema, which resolved after administration of the intravitreal injection of ranibizumab.

management of such a clinical entity remains challenging. Also, in our cases, CNV complicated the initial inflammation, creating an additional therapeutic dilemma, as an established treatment for inflammatory CNV remains inadequate.

Although intravitreal ranibizumab represents the accepted treatment for CNV with a background of agerelated macular degeneration, the latter has not been standardized as the treatment of choice for $\mathrm{CNV}$, due to other etiologies. Nonetheless, it has been shown that the inflammation-induced release of interleukin-1 and tumor necrosis factor- $\alpha$ from the active macrophages stimulates the production of vascular endothelial growth factor (VEGF) by the retinal pigment epithelium, leading to $\mathrm{CNV}$ formation. ${ }^{4}$ Based on that rationale, some reports in the literature highlight the possible beneficial role of intravitreal antiVEGF treatment for inflammatory $\mathrm{CNV}^{5-7}$ After informed consent was obtained, our patients were treated with an intravitreal injection of ranibizumab in order to intercept the VEGF, with a view to surgically removing the traction once the CNV had been controlled. Interestingly, vitreous traction elimination occurred in both our patients shortly after the intravitreal anti-VEGF administration, resulting in a reduction of macular edema.

To date, another case of spontaneous resolution of VMT after ranibizumab administration in a diabetic patient has been reported in the literature. ${ }^{8}$ The authors suggested that the pathophysiological mechanism is based on a dual combined effect: a mechanical effect, whereby an intravitreal injection causes vitreous liquefaction and an increase of 
vitreous volume, and a functional effect arising from the anti-VEGF-induced retinal thickness reduction.

We believe that based on the aforementioned hypothesis, anti-VEGF administration possibly resulted in VMT resolution in our patients in combination with improvement of retinal edema due to $\mathrm{CNV}$ regression. The short period ( 5 days and 7 days) between the intravitreal injection and the spontaneous resolution of VMT in our patients comprises the main factor for suspicion of an etiologic correlation between the injection and the vitreous traction elimination.

\section{Conclusion}

To the best of our knowledge, this is the first reported case of VMT resolution in patients with ocular toxoplasmosis following ranibizumab administration. Of course, further studies are needed in order to adequately determine the possibility of this association. The current report aims to add to the literature two more cases whereby intravitreal anti-VEGF has resulted in spontaneous resolution of VMT syndrome. In addition, the authors aim to add more information with regards to VMT with a background of ocular inflammation, an entity with possibly different microanatomy of the vitreofoveal interface.

\section{Disclosure}

The authors report no conflicts of interest in this work.

\section{References}

1. Gallagher MJ, Yilmaz T, Cervantes-Castañeda RA, Foster CS. The characteristic features of optical coherence tomography in posterior uveitis. Br J Ophthalmol. 2007;91:1680-1685.

2. Oréfice JL, Costa RA, Oréfice F, Campos W, da Costa-Lima D Jr, Scott IU. Vitreoretinal morphology in active ocular toxoplasmosis: a prospective study by optical coherence tomography. Br J Ophthalmol. 2007;91:773-780.

3. Hichichi T, Yoshida A, Trempe CL. Course of vitreomacular traction syndrome. Am J Ophthalmol. 1995;119:55-61.

4. Vinores SA, Youssri AI, Luna JD, et al. Upregulation of vascular endothelial growth factor in ischemic and non-ischemic human and experimental retinal disease. Histol Histopathol. 1997;12:99-109.

5. Rouvas A, Petrou P, Douvali M, et al. Intravitreal ranibizumab for the treatment of inflammatory choroidal neovascularization. Retina. 2011;31(5):871-879.

6. Cornish KS, Lim LT, Imrie F. Management of inflammatory choroidal neovascularization (CNV) secondary to punctate inner choroidopathy in a young female of childbearing age with intra-vitreal ranibizumab and half-fluence photodynamic therapy (PDT): a holistic approach. Semin Ophthalmol. 2012;27(1-2):29-32.

7. Dardabounis D, Alvanos E, Gatzioufas Z, Panos GD. Intravitreal ranibizumab in choroidal neovascularisation due to multifocal choroiditis and panuveitis syndrome. BMJ Case Rep. Epub July 17, 2013.

8. Rouvas A, Petrou P, Ladas I, Neamonitou G, Vergados I. Spontaneous resolution of vitreomacular traction following ranibizumab (Lucentis) injection. Eur J Ophthalmol. 2008;18:301-303.
Therapeutics and Clinical Risk Management

\section{Publish your work in this journal}

Therapeutics and Clinical Risk Management is an international, peerreviewed journal of clinical therapeutics and risk management, focusing on concise rapid reporting of clinical studies in all therapeutic areas, outcomes, safety, and programs for the effective, safe, and sustained use of medicines. This journal is indexed on PubMed Central, CAS,

\section{Dovepress}

EMBase, Scopus and the Elsevier Bibliographic databases. The manuscript management system is completely online and includes a very quick and fair peer-review system, which is all easy to use. Visit $\mathrm{http}: / / \mathrm{www}$. dovepress.com/testimonials.php to read real quotes from published authors. 